\title{
Extracellular vesicles of ETV2 transfected fibroblasts stimulate endothelial cells and improve neovascularization in a murine model of hindlimb ischemia
}

\author{
Phuc Van Pham • Ngoc Bich Vu • Thuy Thi-Thanh Dao • \\ Ha Thi-Ngan Le - Lan Thi Phi • Oanh Thuy Huynh • \\ Mai Thi-Hoang Truong • Oanh Thi-Kieu Nguyen • Ngoc Kim Phan
}

Received: 28 December 2016/Accepted: 7 April 2017/Published online: 2 May 2017

(C) Springer Science+Business Media Dordrecht 2017

\begin{abstract}
Ischemia are common conditions related to lack of blood supply to tissues. Depending on the ischemic sites, ischemia can cause different diseases, such as hindlimb ischemia, heart infarction and stroke. This study aims to evaluate how extracellular vesicles (EVs) derived from ETV2 transfected fibroblasts affect endothelial cell proliferation and neovascularization in a murine model of hindlimb ischemia. Human fibroblasts were isolated and cultured under standard conditions and expanded to the 3 th passage before use in experiments. Human fibroblasts were transduced with a viral vector containing the ETV2 gene. Transduced cells were selected by puromycin treatment. These cells were further cultured for collection of EVs, which were isolated from culture supernatant. Following co-culture with endothelial cells, EVs were evaluated for their effect on
\end{abstract}

P. Van Pham $(\bowtie) \cdot$ N. B. Vu · T. T.-T. Dao ·

H. T.-N. Le - L. T. Phi - O. T. Huynh ·

M. T.-H. Truong · O. T.-K. Nguyen · N. K. Phan

Laboratory of Stem Cell Research and Application,

University of Science, Vietnam National University,

Ho Chi Minh City, Vietnam

e-mail: pvphuc@hcmuns.edu.vn

N. B. $\mathrm{Vu}$

e-mail: vbngoc@hcmus.edu.vn

T. T.-T. Dao

e-mail: dttthuy@hcmus.edu.vn

H. T.-N. Le

e-mail: 1tnha@hcmus.edu.vn endothelial cell proliferation and were directly injected into ischemic tissues of a murine model of hindlimb ischemia. The results showed that EVs could induce endothelial cell proliferation in vitro and improved neovascularization in a murine model of hindlimb ischemia. Our results suggest that EVs derived from ETV2-transfected fibroblasts can be promising noncellular products for the regeneration of blood vessels.

Keywords Extracellular vesicles - EVs - ETV2 . Fibroblasts $\cdot$ Ischemia $\cdot$ Hindlimb ischemia
Abbreviations
ADSCs Adipose derived stem cells
ALI Acute hindlimb ischemia
EPCs Endothelial progenitor cells
ETV-2 ETS variant 2
L. T. Phi
e-mail: ptlan@hcmus.edu.vn
O. T. Huynh
e-mail: htoanh@hcmus.edu.vn
M. T.-H. Truong
e-mail: tthmai@hcmus.edu.vn
O. T.-K. Nguyen
e-mail: ngtkoanh@hcmus.edu.vn
N. K. Phan
e-mail: pkngoc@hcmus.edu.vn 
EVs Extracellular vesicles

HUVECs Human umbilical vein endothelial cells

MCECs Mouse cardiac endothelial cells

MSCs Mesenchymal stem cells

PBMCs Peripheral blood mononuclear cells

PBS Phosphate buffer saline

VEGFR2 Vascular endothelial growth factor receptor 2

\section{Introduction}

Ischemia is a condition which results from limited blood supply to tissues. Although some kinds of ischemia do not affect patient survival, certain kinds can cause extreme diseases, including hindlimb ischemia, stroke and myocardial infarction. There has been rise of ischemia associated with diabetes and high blood pressure; thus, understanding ways to prevent or treat ischemia is essential. In this study, acute hindlimb ischemia (ALI) was used as a model to investigate treatments for ischemia.

ALI (and ischemia in general) can be treated by stem cell therapy, which has shown some promising results. Unlike traditional therapies, stem cell transplantation can help create new blood vessels via angiogenesis or vasculogenesis. Stem cells, such as bone marrow derived stem cells (BMSCs) and adipose tissue derived stem cells (ADSCs), have been studied in preclinical trials (Hao et al. 2014; Liu et al. 2015; Park et al. 2014; Qin et al. 2014; Yoshida et al. 2016) and clinical trials of ALI therapy (Amann et al. 2008, 2009; Ammar et al. 2015; Gremmels et al. 2014; Gupta et al. 2013; Iafrati et al. 2011; Peeters Weem et al. 2016; Saliutin et al. 2014; Teraa et al. 2015). In addition, menstrual blood cells ( $\mathrm{Vu}$ et al. 2015), umbilical cord blood derived endothelial progenitor cells (Van Pham et al. 2014), placenta derived mesenchymal stem cells (MSCs) (Xie et al. 2016; Zhang et al. 2014), and Wharton's jelly derived endothelial progenitor cells (Shen et al. 2013) have been studied in preclinical trials of ALI.

Although results have shown promise, stem cell therapy holds several limitations; cell preparation is very time-consuming, stem cell processing and cultures are expensive, and there are risks related to immunogenicity from whole cell transplantation. Thus, next generation therapies using exosomes or extracellular vesicles (EVs) have been suggested as a replacement for whole cell therapy. Exosomes or EVs are cell-derived vesicles which are present in many fluids, including blood, urine and cultured cell medium (Keller et al. 2006; van der Pol et al. 2012). Some reports have suggested that exosomes have a diameter of 30-100 nm, while EVs have a diameter of 100-1000 nm (Booth et al. 2006). Both exosomes and EVs contain RNAs and proteins, and have been identified to play an important role in cell-cell communication. Indeed, tumor cell derived exosomes and EVs in hepatocellular carcinoma were found to promote invasion, metastasis, immune evasion and modulation ( $\mathrm{Wu}$ et al. 2016), and motility of immortalized hepatocytes (He et al. 2015). Exosomes and EVs from MSCs can suppress angiogenesis by downregulating VEGF expression in breast cancer cells (Lee et al. 2013), promoting fracture healing in mice (Furuta et al. 2016), accelerating skeletal muscle regeneration (Nakamura et al. 2015), and suppressing myofibroblast differentiation (Fang et al. 2016). The biological activities carried out by exosomes and EVs include transfer of oncogenic proteins and RNAs (He et al. 2015) which inhibit breast cancer, transfer of a group of specific microRNAs (miR-21, miR-23a, miR-125b and miR-145) found to play key roles in suppressing myofibroblast formation (Fang et al. 2016), and transfer of miR-146b which causes inhibition of glioma growth (Katakowski et al. 2013). More interestingly, exosomes and EVs have been shown to be safe when used in animals (Sun et al. 2016; Zhao et al. 2015) and in humans (Besse et al. 2016; Dai et al. 2008; Pitt et al. 2016).

In recent years, the composition of RNAs and proteins inside EVs were modified to produce EVs with particular biological activities. Wen et al. (2016) transfected human BMSCs with a plasmid expressing the siFas and anti-miR-375 genes, and collected EVs from these cells. The authors demonstrated that the EVs could suppress immune reaction by inhibiting peripheral blood mononuclear cell (PBMC) proliferation and enhancing regulatory $\mathrm{T}$ cell (Treg) function (Wen et al. 2016). Similarly, Fan et al. (2013) used EVs derived from a MHC class II molecule-expressing murine colon cancer cell line (CT26-CIITA) that had been transduced with the CIITA gene, to induce antitumor immunity (Fan et al. 2013).

In this study, fibroblasts were transduced with ETV-2, a master gene regulator of angiogenesis. In fact, ETV2 regulates various signaling pathways and 
functions as an essential regulator for vasculogenesis and hematopoiesis. In embryogenesis, ETV2 and GATA2 regulate the expression of SPI1 via binding to its promoter of SPI1 (Shi et al. 2014). It also regulates cardiac development (Schupp et al. 2014), and vascular regeneration (Park et al. 2016). Previously, we and other groups have shown that ETV-2 transduced fibroblasts can be directly converted into endothelial progenitor cells (EPCs) (Ginsberg et al. 2015; Morita et al. 2015; Van Pham et al. 2016). Therefore, this study used fibroblasts as targets for direct conversion using ETV-2 vector.

This study was aimed at investigating the effects of EVs derived from ETV-2 transduced fibroblasts, on endothelial cell proliferation as well as neovascularization in a mice model of hindlimb ischemia. Understanding the role of EVs on proliferation and angiogenesis would potentially aid in the design and rationale for use of EVs for ischemia therapy.

\section{Materials-methods}

Dermal fibroblast isolation and proliferation

Foreskin was collected from a donor who completed a consent form at the hospital. Foreskin was stored in PBS solution at $4{ }^{\circ} \mathrm{C}$ and transferred to the laboratory for isolation and culture of fibroblasts, as described in previous studies (Nahm et al. 2002). Briefly, the samples were cut into small pieces, placed into wells, and allowed to adhere for $5 \mathrm{~min}$ at room temperature (RT). DMEM medium supplemented with $10 \%$ FBS and $1 \times$ anti-mitotic-mycotic solution was then added to the wells and the cultures were maintained at $37{ }^{\circ} \mathrm{C}$, $5 \% \mathrm{CO}_{2}$. The cultures were sub-cultured when cells reached $70-80 \%$ confluence. Human fibroblast (HFs) were sub-cultured to the 3rd passage prior to use in experiments. Human umbilical vein endothelial cells (HUVECs) were purchased from Life Technologies (Carlsbad, CA, USA).

ETV-2 lenti viral vector preparation

The human ETV2 expression vector (pF1KB9707) was purchased from Addgene (Cambridge, MA, USA). ETV2 was cloned into the vector backbone pSIN4EF1alphaIRES-Puro (Plasmid \#61061; Addgene, Cambridge, MA, USA) to generate pSIN4-EF1a-ETV2-
IRES-Puro. All coding sequences in the expression vector were confirmed with the GenomeLab System (Beckman Coulter, Brea, CA, USA). The ETV2 vector was then transfected into HEK293T cells, along with pCMV-VSV-G-RSV-Rev and pCMV-dR8.2 (Addgene). $18 \mathrm{~h}$ after transfection, the medium was replaced with fresh culture medium. The lentiviruscontaining medium was collected $48 \mathrm{~h}$ later, passed through a $0.45-\mu \mathrm{m}$ filter, and concentrated using centrifugation $\left(8400 \times g\right.$ at $4{ }^{\circ} \mathrm{C}$ for $\left.16 \mathrm{~h}\right)$. The lentivirus pellets were resuspended in PBS at $10^{7} \mathrm{IFUs} / \mathrm{mL}$.

Transfection of ETV-2 vector in dermal fibroblasts and cell selection

HFs were plated on 12 -well plates at $7 \times 10^{4}$ cells per well and $24 \mathrm{~h}$ later were infected with $10 \mu \mathrm{L}$ of concentrated lentivirus particles with $5 \mu \mathrm{g} / \mathrm{mL}$ protamine. Plates were plated in hypoxia condition with 5\% $\mathrm{O}_{2}, 5 \% \mathrm{CO}_{2}$, and $37^{\circ} \mathrm{C}$. Another $48 \mathrm{~h}$ later, cells were washed twice with PBS and cultured on 6-cm dishes coated with Cellstart (Thermo Scientific, Waltham, MA, USA) in EGM-2 medium under hypoxic conditions. After 1 week, cells were selected with culture medium supplemented with $10 \mathrm{ng} / \mathrm{mL}$ puromycin for $36 \mathrm{~h}$. Then, the medium was changed with fresh medium without puromycin. The cells were allowed to proliferate until enough cells could be collected for cell sorting. Only CD31 + cells were sorted by FACSJazz Cell Sorter System (BD Biosciences, San Jose, CA, USA) and used for EVs production. Sorted cells were reconfirmed for CD31 expression by flow cytometry using the FACSCaibur system (BD Biosciences).

\section{Production of EVs}

$\mathrm{EV}$ isolation was performed with a commercial kit (Thermo-Fisher Scientific, Waltham, MA, USA). Briefly, the cell supernatant was collected and stored at $2-8{ }^{\circ} \mathrm{C}$ until use. All supernatant samples were centrifuged at $2000 \mathrm{~g}$ for $30 \mathrm{~min}$ to remove cells and debris. The supernatant was transferred to a new tube without disturbing the pellet. The reagent (from the kit) was added to the supernatant at a ratio of $0.5: 1$ reagent to supernatant. This mixture was carefully mixed and incubated overnight at $2-8{ }^{\circ} \mathrm{C}$. Finally, EVs were collected from the bottom of the tubes after centrifugation at $10,000 \mathrm{~g}$ for $1 \mathrm{~h}$ at $2-8{ }^{\circ} \mathrm{C}$. The pellet was resuspended in PBS for further use in experiments. 
EV characterization

EVs were observed under transmission electronic microscope (TEM) to detect and determine the EV diameter. The markers of EVs, CD81 and CD63, were assessed and identified by flow cytometry. Briefly, EV preparations $(5-10 \mu \mathrm{g})$ were incubated with $5 \mu \mathrm{l}$ of 4- $\mu \mathrm{m}$-diameter aldehyde/sulfate latex beads (ThermoFisher Scientific) and resuspended into $400 \mu \mathrm{L}$ PBS containing $2 \%$ fetal bovine serum (FBS). Then, EVcoated beads $(20 \mu \mathrm{L})$ were incubated with the following antibodies: anti-CD63-FITC (Santa Cruz Biotech, Dallas, TX, USA) and anti-CD81-PE (Santa Cruz Biotech), anti-CD9-FITC (Santa Cruz Biotech) for 30 min at $4{ }^{\circ} \mathrm{C}$, then analyzed on a FACSCalibur flow cytometer (BD Biosciences).

\section{Endothelial cell proliferation assay}

Cell proliferation was evaluated by xCelligence assay. HUVECs were seeded in E-plates at 5000 cells/well. Before that, $50 \mathrm{uL}$ of medium was added into the plates to read the baseline. The E-plate with cells was left for $30 \mathrm{~min}$ and then put into the xCelligence system (ACEABIO, San Diego, CA, USA). Cell proliferation was monitored via cell index and doubling time for $168 \mathrm{~h}$. There were 3 groups tested for their effect on HUVEC proliferation; the first group (G1) was the placebo group, i.e., cell culture medium supplemented with PBS; the second group (G2) and third group (G3) were the treatment groups containing $50 \mu \mathrm{g} / \mathrm{ml}$ of EVs (EXO50) and $100 \mu \mathrm{g} / \mathrm{ml}$ of EVs (EXO100), respectively (the EVs were diluted in PBS).

\section{Murine model of hindlimb ischemia}

6- to 12-month old mice were used for the ischemic hindlimb model. All animal protocols and experiments were prepared, based on the "Guide for the Care and Use of Laboratory Animals" from the local research institution, and approved by the Committee of Care and Use of Laboratory Animals. Acute hindlimb ischemic mice were established according to previously published protocols (Vu et al. 2014). Briefly, the mice were anesthetized using $7.5 \mathrm{mg} / \mathrm{kg}$ zoletil. Hairy thighs were shaved and an incision, approximately $1 \mathrm{~cm}$ long, was made along the thigh skin. The fat thighs were removed and the femoral arteries near the abdomen were dissected from the veins and nerves, and ligated at two positions. Between the two ligated artery positions, a burn was made using an electronic cutting machine (ESU-X, Geister, Tuttlingen, Germany). Finally, the skin was stitched and the wound area was covered in povidone-iodine.

EV injection in acute hind limb ischemic mice

Acute hind limb ischemic mice were divided into 2 groups (15 mice/group). Group I (GI) contained nontreated mice (placebo group; mice were injected with PBS). Group II (GII) contained mice injected with a dose of $100 \mu \mathrm{L}$ of $100 \mu \mathrm{g} / \mathrm{ml} \mathrm{EVs}$. EVs or PBS were directly injected into the muscle at the burn sites at day 0 after models were produced. All mice were followed up to 4 weeks ( 30 days) to evaluate the effects of the grafts.

Evaluation of recovery of damaged limbs after EV injection

The degree of ischemic damage was assessed through indicators, such as skin color changes, swelling, and grade of limb necrosis. The latter was evaluated and classified according to the guidelines, as follows, of Goto et al. (2006): Grade 0, normal limb without swelling, necrosis or atrophy of muscle; Grade I, necrosis limited to the toes; Grade II, necrosis extending to the foot; Grade III, necrosis extending to the knee; and Grade IV, necrosis extending to the hip or loss of whole hind limb.

The blood flow recovery was evaluated by changing of peripheral capillary oxygen saturation $\left(\mathrm{spO}_{2}\right)$ at toes before burning the blood vessels, and after treating with EVs for 0,3 , or 30 days. The spO-2 was measured by the pulse oximeter (Omron, Osaka, Japan). The trypan blue flow assay was also used to evaluate blood flow. Briefly, $1 \%$ trypan blue was injected into the tail vein. If blood vessel recovery occurred at the burn sites, the trypan blue dye would be delivered to the toes and feet, which would stain blue. The time needed for staining of toes and feet after injection of trypan blue was determined based on a stopwatch (in seconds).

Histological analyses of limb tissues were done at 3 and 30 days after transplantation as the previous published study ( $\mathrm{Vu}$ et al. 2016). The mice were 
euthanized and hindlimb muscle was collected. Samples were frozen in optimal cutting temperature compound (Thermo) and cut at cross-sections of $10 \mu \mathrm{m}$ thickness using a cryostat (Leica, Richmond Hill, ON, Canada). Tissue section slides were then stained with hematoxylin-eosin (H\&E) and assessed by microscopy (Carl-Zeiss, Oberkochen, Germany).

\section{Statistical analysis}

Statistical analyses of all endpoints were performed using the two-sided Student's t test or one-way analysis of variance. All data are presented as mean $\pm \mathrm{SD} ; p<0.05$ was considered statistically significant. Data were analyzed with GraphPad Prism 6.0 software.

\section{Results}

Dermal fibroblast isolation and proliferation

From the tissue expansion culture, fibroblasts started to migrate out from the tissues and adhere to the flask surface at day 4 after seeding (Fig. 1a). The fibroblasts proliferated from day 10 onward and reached full confluence by day 15 (Fig. 1b). The fibroblast population become homogenous at the 3rd cell culture passage. To evaluate cell homogeneity, the cell population was analyzed with flow cytometry for expression of CD90. The results showed that $100 \%$ cells expressed the CD90 marker (Fig. 1c). These cells were used in subsequent experiments.

Fibroblasts were successfully transduced

with a lentiviral vector expressing $E T V$-2 gene

Per previously published studies, the transduced fibroblasts were cultured until enough cells could be collected for subsequent cell sorting (Fig. 2a), with 6.51\% CD31 positive cells (Fig. 2d). ETV2-transduced cells were selected by puromycin resistance for $7 \mathrm{~d}$. The results showed that about $80 \%$ cells were eliminated with puromycin treatment (Fig. 2b), with about $29.81 \%$ CD31 positive cells (Fig. 2e). The surviving cells were subsequently cultured for an additional 2 weeks, and then used to sort for CD31 + cells (Fig. 2c). The purity of the cell population was verified, with more than $95 \%$ of cells positive for CD31 expression (Fig. 2f). Cells were continually expanded for isolation of EVs.

\section{$\mathrm{EV}$ isolation and characterization}

Extracted EVs were observed by TEM; almost all particles were in the 30-100 nM range in size (Fig. 3a, b). Expression of CD9, CD63 and CD81 was confirmed by flow cytometry. The results showed that 100\% EVs expressing CD9 (Fig. 3d), $76.54 \pm 8.19 \%$ EVs expressing CD63 (Fig. 3e), $48.61 \pm 9.14 \%$ EVs expressing CD81 (Fig. 3f).

EVs stimulated endothelial cell proliferation and roles of RNAs components

The eXcelligence analysis showed that HUVEC endothelial cells proliferated more rapidly in the group where EVs were added to culture medium, as compared to control (G2, and G3 vs G1) (Fig. 4a). In the first $36 \mathrm{~h}$ in the same medium, the proliferation curves in the 3 groups G1, G2 and G3 were similar. However, after replacing the media, different for G1, $\mathrm{G} 2$ and $\mathrm{G} 3$, the cell proliferation curves became significantly different at $96 \mathrm{~h}$. Figure $4 \mathrm{a}$ shows that after $96 \mathrm{~h}$, the proliferation curve of cells in G2 and G3 was clearly higher than in G1, and G3 also was clearly higher than in $\mathrm{G} 2$ suggesting that the cell proliferation rate in G3 was faster than for cells in G2 and in G2 was faster than for cells in G1. Interestingly, after $132 \mathrm{~h}$, cells in G1 entered rapid senescence where the proliferation rate suddenly decreased. At the same time, cells in G2 and G3 also entered to senescence but slowlier. The doubling times were analyzed and showed that EV supplement significantly reduced the doubling time of cells- from $56 \pm 5.2 \mathrm{~h}$ (in placebo, G1) to $41 \pm 1.37 \mathrm{~h}$ (in G2), to $37 \pm 1.75 \mathrm{~h}$ (in G3) (Fig. 4b).

EVs efficiently increased the recovery of hindlimb ischemia in a murine model of ischemia

The effect of EVs on the recovery of ischemic hindlimb in mice was observed for 30 days. The grade of limb necrosis was evaluated and classified according to the guidelines, as follows, of Goto et al. (2006) (Figure 5). The results showed that injection of EVs significantly decreased the necrosis of the hindlimb, as compared to the placebo group that received an 

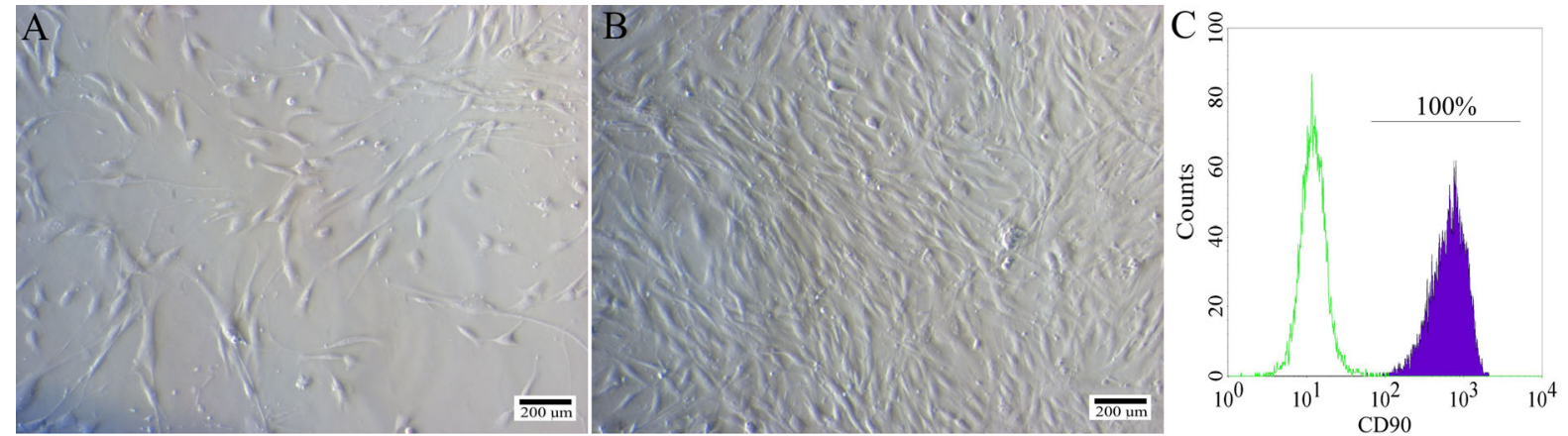

Fig. 1 Dermal fibroblast isolation and expansion. The dermal tissues were cultured to obtain migrated fibroblasts (a); proliferating cells reached confluency at day 15 (b); cells were a homogenous population, confirmed by CD90 expression (c)
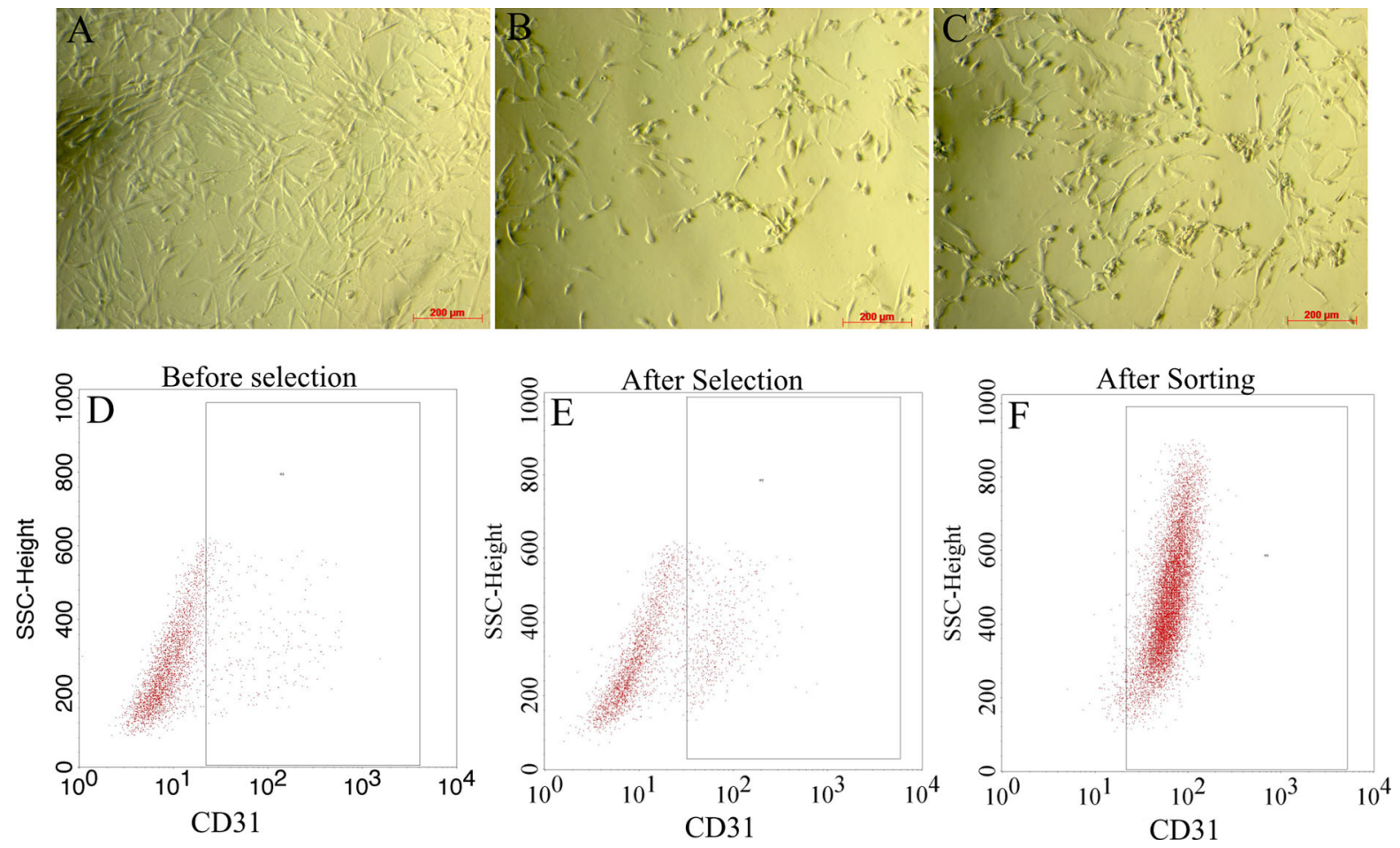

Fig. 2 Transduced fibroblasts were selected and proliferated. ETV2-transduced cells were cultured after transduction (a), selected by puromycin resistance for 7 days (b), and sorted

based on CD31 positive cells (c). CD $31^{+}$cells were analyzed in transduced samples (d), puromycin selected samples; and CD31 ${ }^{+}$cells sorted samples $(\mathbf{e})$

injection of PBS (Fig. 6a). In the GII (EVs injected) group, $33.33 \%$ of mice completed recovered, $16.67 \%$ had a necrotic grade I, $33.33 \%$ had necrotic grade III, $8.33 \%$ had necrotic grade IV, and $8.33 \%$ died. In the GI (placebo injected) group, only $16.67 \%$ of mice completed recovered, $41.67 \%$ had necrotic grade I, $8.33 \%$ had necrotic grade IV and $33.33 \%$ died. The results show that EV injection increases recovery of mice by twofold (33.33 vs. $16.67 \%$, for GII vs GI,

respectively). The death of mice also significantly decreased (33.33 vs. 8.33\%; for GI vs. GII, respectively) (Fig. 6a).

The $\mathrm{spO}_{2}$ results showed that after injection with $\mathrm{EVs}, \mathrm{spO}_{2}$ in GII increased more than in GI; however, there was no statistical difference in $\mathrm{spO}_{2}$ at day 3 and day 30 (Fig. 6b). The trypan blue assay showed that in surviving mice without loss of legs, the average time for staining of toes and feet with trypan blue was 

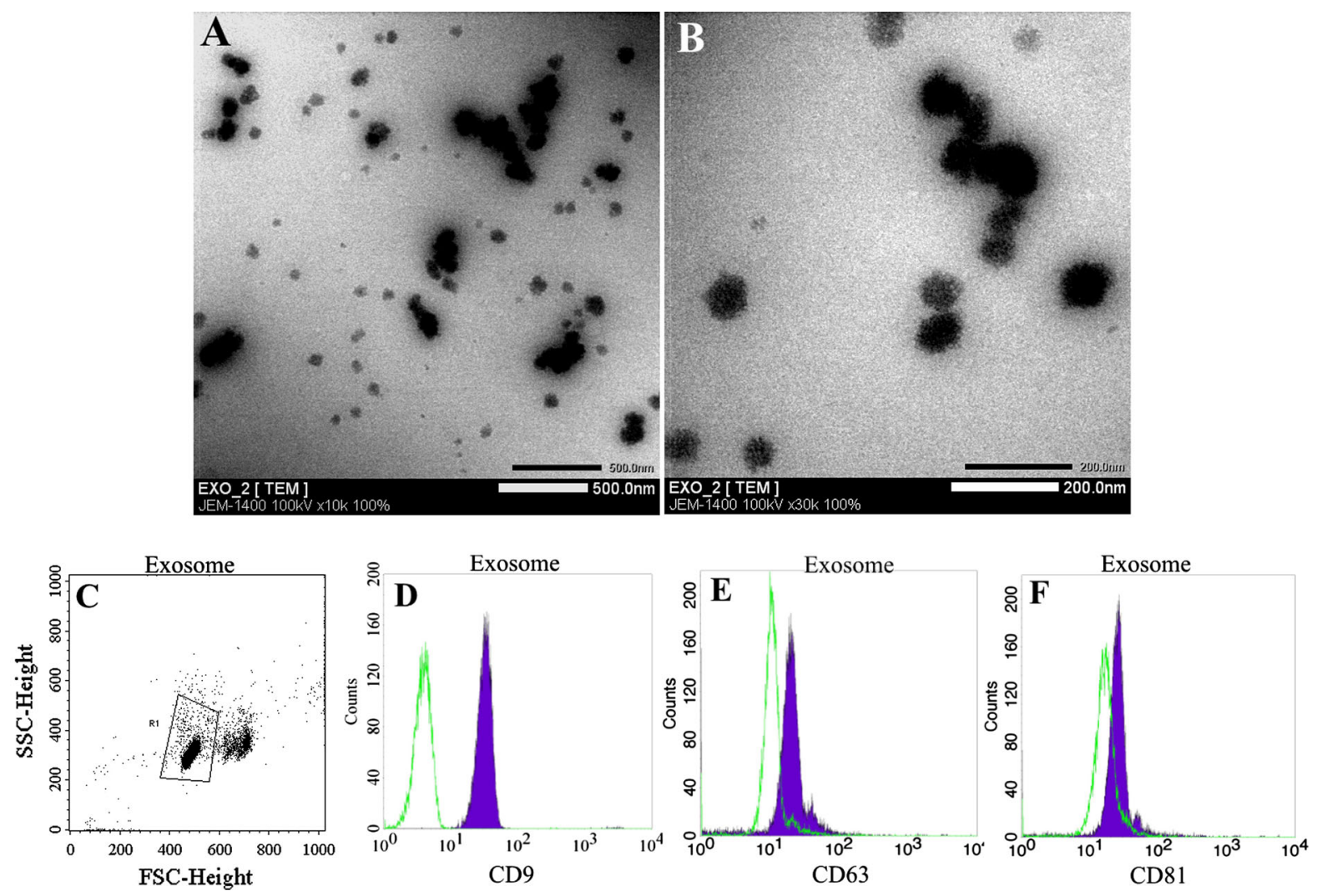

Fig. 3 Extracellular vesicles derived from ETV2-positive fibroblasts. Extracellular vesicles with diameter range of 30-100 nm were determined by TEM (a, b). The extracellular

vesicles were bound to beads and gated with single beads (c) for analysis of CD9 (d), CD63 (e), and CD81 (f) expression

significantly different between GI with GII, and with normal mice. In normal mice and in those with normal hindlimb, the feet and toes of the mice become blue $20 \mathrm{~s}$ after trypan blue injection into the tail vein. However, ischemic hindlimbs require $72.25 \pm 94.35 \mathrm{~s}$ to become blue in GI mice and $380 \pm 110.9 \mathrm{~s}$ in GII mice. After 20 and 30 days, there were no significant differences between GI and GII ( $24.17 \pm 6.646$ s vs. 25 s on day 20 ; and 20 s vs. $21.67 \pm 2.887 \mathrm{~s}$ on day 30 , for GI and GII, respectively) (Fig. 6c).

These observations were supported by histological analysis (Fig. 7). The thigh muscles at treated sites of groups I \& II mice were collected to analysis the histological structures and the neo-angiogenesis. The results of H\&E staining also showed that in the normal mouse, skeletal muscle was arranged in bundles, in an orderly fashion. Their nuclei were located at the periphery of the muscle fiber; and their cytoplasmic staining was shown in pink and the cell nuclei staining

in purple. Meanwhile, tissue necrosis occurred in the group I (Fig. 7a) and group II (Fig. 7c) at day 3. The cytoplasm showed shrinkage and tissue structure was rearranged. In some samples, the cells were not arranged with a particular order. The nuclei were not aligned along the edge of the cell (plasma membrane), but were concentrated near or in the cytoplasm. After 30 days, the tissue structure of both group I (Fig. 7b) and group II (Fig. 7d) that could survive and did not lose the legs were significantly improved. Particularly, the tissue structure of EVs injected mice was similar to those of normal mice at day 30 of treatment. Moreover, blood vessel density were higher in EVs injected mice compared to PBS injected mice.

\section{Discussion}

Recently, exosomes as well as EVs from various cells have shown varying biological activities. For 

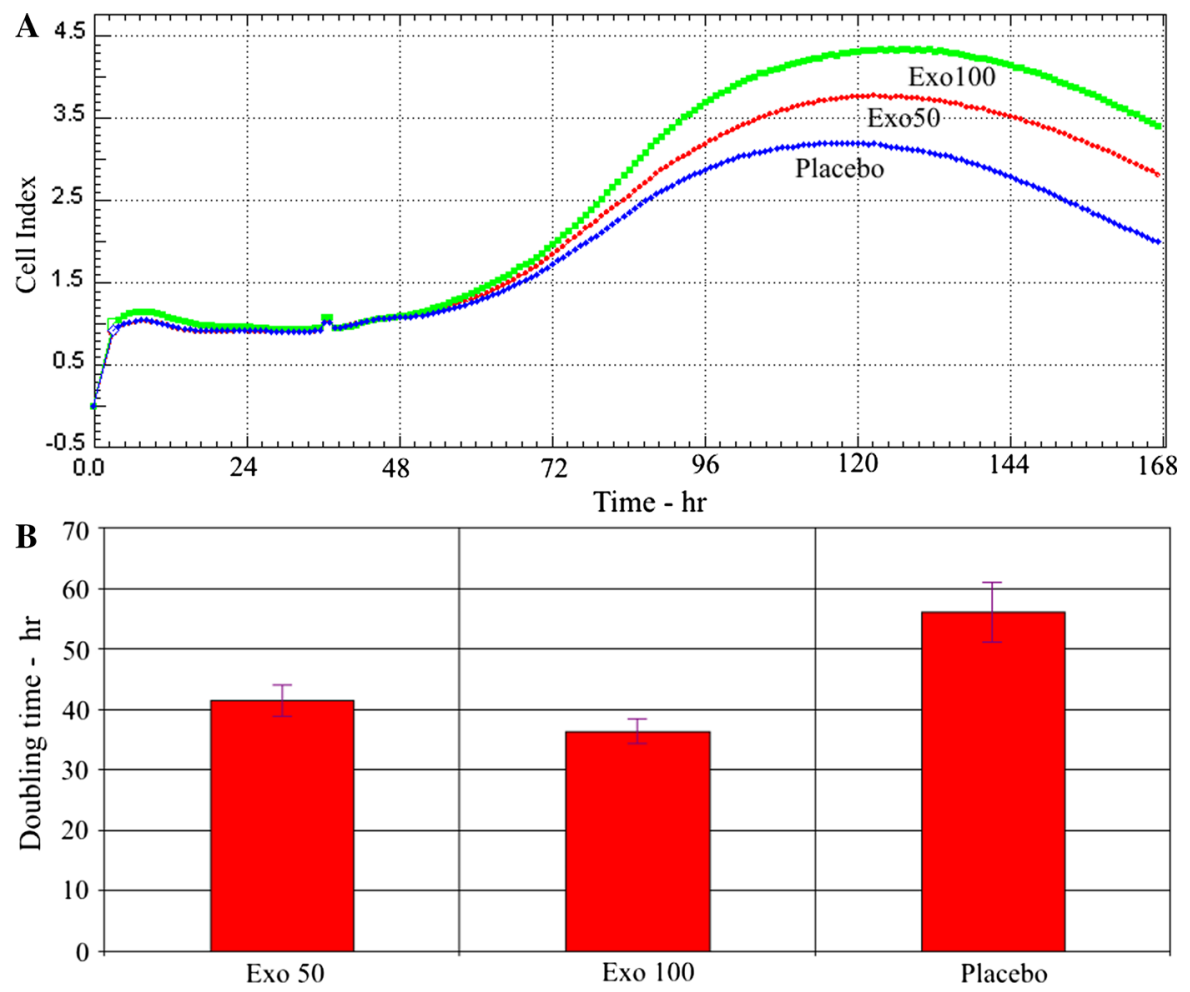

Fig. 4 Extracellular vesicles derived from ETV2 positive fibroblasts stimulated proliferation and inhibited senescence of HUVECs. The proliferation curves of HUVECs in group G1

example, EVs from ADSCs promote endothelial cell angiogenesis (Liang et al. 2016). Transfer of miR125a from ADSCs to endothelial cells via exosomes is the reason for this effect (Liang et al. 2016). Exosomes from BMSCs induce proliferation and migration of normal and chronic wound fibroblasts, enhance in vitro angiogenesis (Shabbir et al. 2015), and promote periodontal tissue regeneration (Kawai et al. 2015). EVs from umbilical cord derived MSCs can suppress myofibroblast differentiation by inhibiting the TGF-beta/SMADs pathway (Fang et al. 2016), EVs from cardiomyocytes isolated from adult GotoKakizaki (GK) rats can inhibit the proliferation and migration of mouse cardiac endothelial cells (MCECs) (Wang et al. 2014), and those from embryonic stem cells promote endogenous repair mechanisms and enhance cardiac function following myocardial infarction (Khan et al. 2015). Moreover, EVs from human urine-derived stem cells accelerate skin wound healing by promoting angiogenesis in rats (Fu et al. 2014; Yuan et al. 2016) and prevent kidney complications from type I diabetes (Jiang et al. 2016). EVs from (placebo), groups G2, G3 (extracellular vesicles supplement, Exo50 and Exo100, respectively) are shown (a) and are supported by the doubling time analysis (b)

human-induced pluripotent stem cell-derived MSCs have been shown to promote angiogenesis in hindlimb ischemia in mice (Hu et al. 2015), promote collagen synthesis and angiogenesis (Zhang et al. 2015), and induce repair of bone defects in osteoporotic rats (Qi et al. 2016). In mouse models, Geiger et al. (2015) demonstrated that human fibrocyte-derived exosomes successfully accelerated the wound healing process in genetically diabetic mice (Geiger et al. 2015).

Our study herein confirms that EVs derived from ETV-2 transfected fibroblasts can stimulate endothelial cell proliferation and neo-angiogenesis in an ischemia hindlimb mouse model. Firstly, ETV2 expressing fibroblasts were successfully isolated and cultured. The cells were confirmed as dermal fibroblasts from their spindle shape and high expression of CD90, considered as a popular marker of fibroblasts (Johnson et al. 2016; Kisselbach et al. 2009). The cells were capable of being transduced with a lentiviral vector containing the ETV-2 gene. All transduced fibroblasts showed resistance to puromycin; this characteristic is related to the selective puromycin 

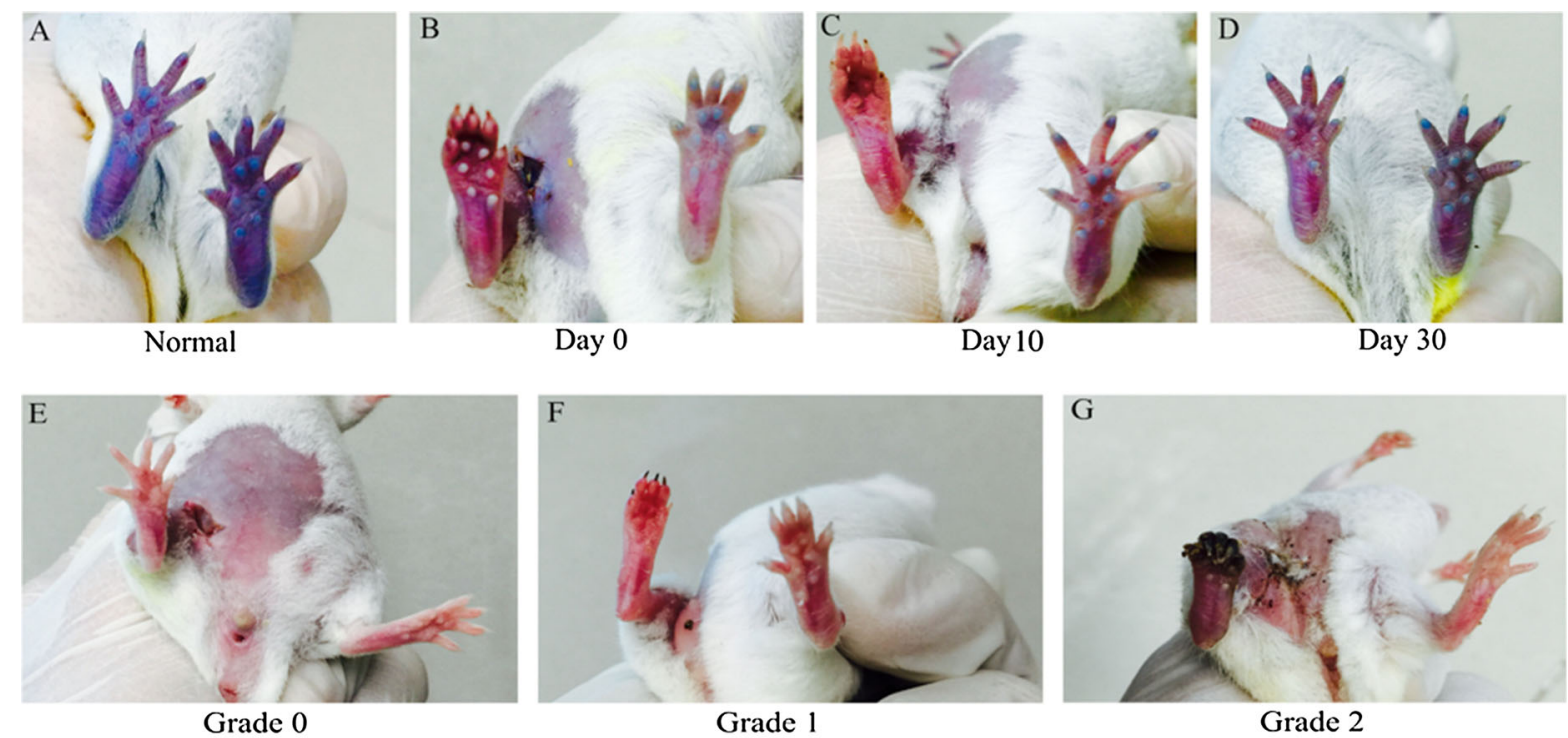

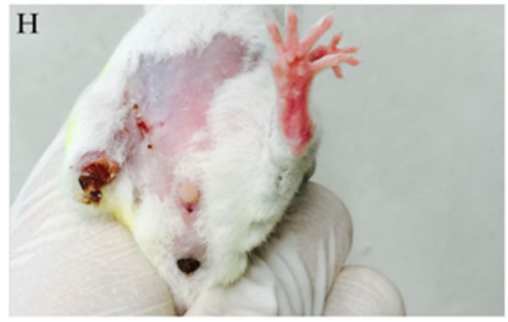

Grade 3

Fig. 5 The grade of limb necrosis was evaluated and classified according to the guidelines, as follows, of Goto et al. (2006). The trypan blue flow assay was used to evaluate the blood flow. The average time after injection of trypan blue at the tail vein to stain toes and feet were determined at normal mice (a), and on

resistance gene encoded by the lentiviral vector. Moreover, expression of ETV-2 by transduced cells was also confirmed by real-time RT-PCR.

Subsequently, EVs from ETV-2 positive fibroblasts were successfully isolated with the use of commercial kits. These EVs contained both RNAs and proteins, and were positive for CD81 and CD63. Importantly, these EVs significantly stimulated endothelial cell proliferation. Indeed, the effects of the EVs included increased HUVEC proliferation rate and decreased doubling time. Our results suggest that materials inside the EVs play an important role in stimulating HUVEC proliferation. In fact, according to a previous study from our laboratory, ETV-2 transduced fibroblasts are capable of directly conversing into endothelial progenitor cells (Van Pham et al. 2016). Before this study, some studies suggested that ETV-2 may

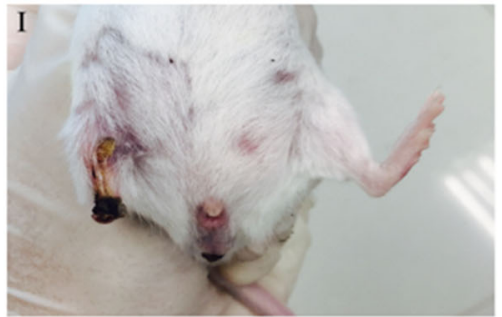

Grade 4

day 0 (b), on day 10 (c) and on day 30 (d) in animals after induction of hindlimb ischemia. The grades of limb necrosis were classified as Grade 0 (e), Grade I (f), Grade II (g), Grade III (h), Grade IV (i)

have a role in angiogenesis as well as direct reprogramming of fibroblasts to endothelial progenitor cells (Ginsberg et al. 2012, 2015; Morita et al. 2015). The studies showed that about $1-7 \%$ of ETV2 transduced fibroblasts go on to become EPCs. These EPCs exhibit full characteristics of natural EPCs, such as expression of CD31 and VEGFR2, and can form blood vessel-like capillaries (Morita et al. 2015; Van Pham et al. 2016). These studies suggest that fibroblasts from our study may be capable of conversion into EPCs.

In concordance with our observations from this study, some recently published studies have shown that exosomes as well as EVs derived from EPCs can induce multiple properties. Human umbilical cord blood EPCs derived EVs can protect against acute kidney injury by inhibition of endothelial cell apoptosis (Burger et al. 2015). These cells can also enhance 

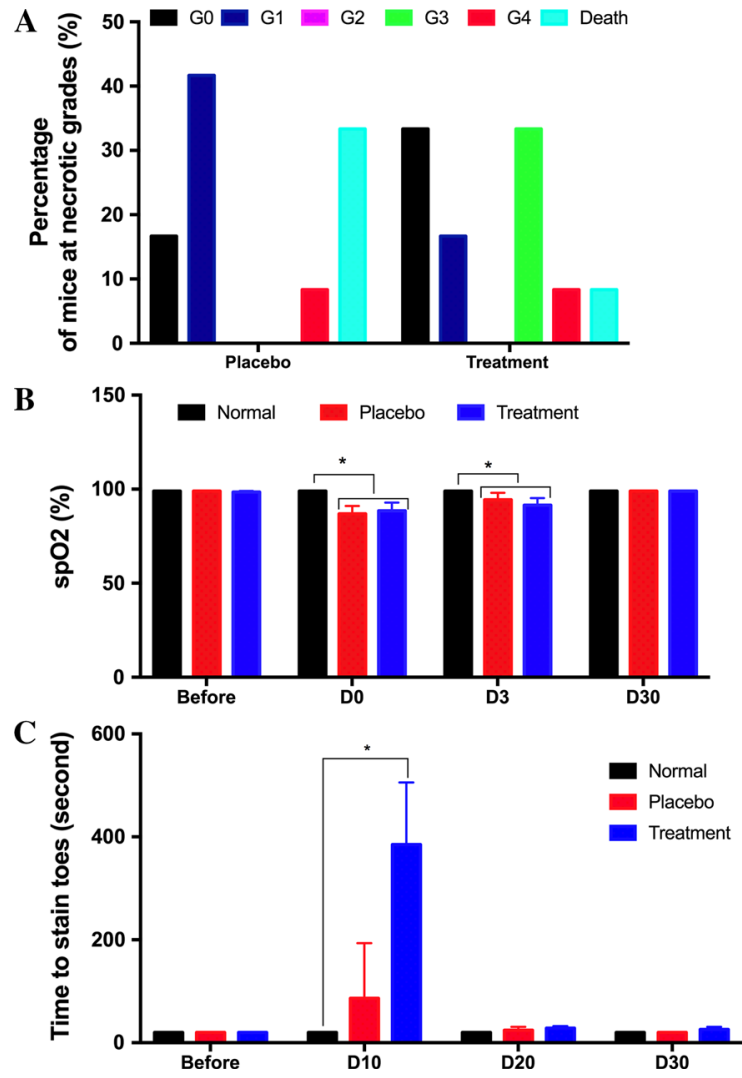

Fig. 6 Extracellular vesicles improve ischemic hindlimb in a murine model. Mice were injected with PBS as considered as Placebo (Placebo); while in the treatment group, mice were injected with a dose of $100 \mu \mathrm{L}$ of $100 \mu \mathrm{g} / \mathrm{ml} \mathrm{EVs}$ (Treatment). Extracellular vesicles efficiently reduced the percentage of mouse deaths due to ischemia, increased the percentage of fully recovered mice, and decreased the percentage of loss-leg mice (a). These results were supported by blood flow evaluation by $\mathrm{spO}_{2}$ (b) and trypan blue assay (c)

the proliferation, migration and tube formation of vascular endothelial cells in vitro ( $\mathrm{Li}$ et al. 2016b), while suppressing senescence and inducing angiogenesis in human and mouse endothelial cells (van Balkom et al. 2013). Although in this study, we did not determine what the protein and RNA components of the EVs were. In a previous study in the human endothelial cells, van Balkom et al. (2013) suggested that EVs from ECs containing miR-214 could be later transferred to mouse endothelial cells (van Balkom et al. 2013).

In the last part of our study, EVs from directly converted EPCs were shown to be capable of improving hindlimb ischemia in a mouse model. EVs not only decreased the necrosis grade in mice but also increased the survival of mice. EVs injection doubled the percentage of fully recovered mice (with necrosis grade 0 ). The blood flow recovery evaluations also supported this observation. At first look, the results from the spO-2- and trypan blue assays appeared to question the efficacy of EVs. However, these results are suitable, given the physiology and pathophysiology of neo-angiogenesis. Indeed, in the group GI (placebo group), only some mice could fully auto-recover their blood vessels which maintained blood flow into the toes and feet; other mice could not survive or had loss of their ischemic legs after 3 days. At day 10, only mice with legs were used for assessment with trypan blue assay. In the GII (treatment group), EV treatment rescued the mice and in fact, increased the percentage of surviving mice with ischemic legs.

Of note, in the first 10 days, neo-angiogenesis at these legs are being carried out with small vessels so that the time needed to stain blue the toes and feet using the trypan blue assay took longer. These results also showed that neovascularization was present and progressed slowly in EV-treated mice. Only after 30 days, blood vessel networks were fully formed; $\mathrm{spO}_{2}$ and trypan blue assay to stain toes and feet were similar for mice of both GI and GII groups. The histological analysis also supported this observation.

Our results are similar to some very recent studies (Li et al. 2016a, b). Authors used human umbilical cord blood EPCs derived from EVs to treat the wounds. The results showed that EPC-derived EVs could accelerate cutaneous wound healing in diabetic rats ( $\mathrm{Li}$ et al. 2016b), attenuate vascular repair, and accelerate re-endothelialization by enhancing endothelial function ( $\mathrm{Li}$ et al. 2016a).

From the results of this study, we suggest two strategies to use the ETV-2 vector for ischemia treatment. The first way is using EVs from directly converted EPCs, which can be isolated from many sources, such as bone marrow, umbilical cord blood and other sources. These EPCs have a short life-span, slow proliferation, easy differentiation into mature cells, and ability for senescence. The directly converted EPCs are a new choice to produce a large-scale of EPCs and then EPC derived EVs. As non-cellular products, EVs are safe for clinical applications (Han et al. 2016; Sun et al. 2016). The second way is to promote in vivo direct conversion of dermal fibroblasts by ETV-2. The converted fibroblasts in vivo 
Fig. 7 Histological structure analysis after $\mathrm{H} \& \mathrm{E}$ staining at day 3 and 30 after transplantation. Tissue necrosis occurred in the group I (a) and group II (c) at day 3. After 30 days, the tissue structure of both group I (b) and group II (d) that could survive and did not lose the legs were significantly improved, similar to those of normal mice. Moreover, blood vessel density was higher in extracellular vesicles injected mice compared to PBS injected mice. The arrows point to blood vessel
GI (PBS Injection)
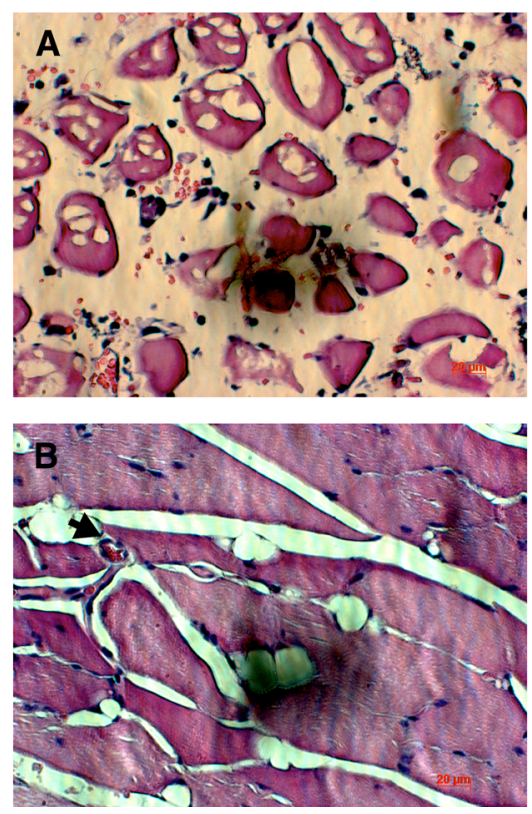

GII (Microvesicle Injection)
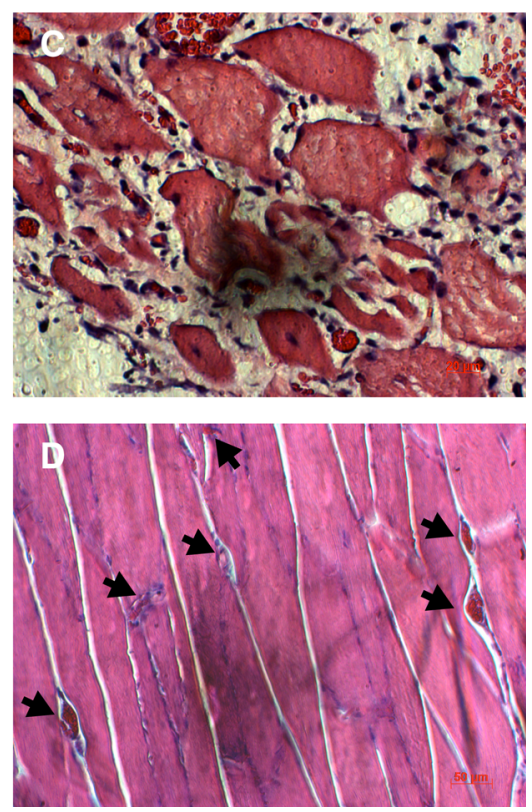

produce EVs, which induce endothelial cells at the ischemic site to regenerate and recover/repair blood vessels.

However, there were still some limitations in this study. The effects of empty viral transfected fibroblasts derived EVs on endothelial cells in vitro and neovascularization in a murine model of hindlimb ischemia have not been evaluated yet. Non-viral ETV2 vector also should be investigated to use these EVs for clinical usage.

\section{Conclusion}

ETV-2 is a master gene regulator of angiogenesis. ETV-2 plays a role in directly converting fibroblasts into endothelial progenitor cells. EVs from these directly converted endothelial progenitor cells or ETV-2 transduced fibroblasts can stimulate endothelial cell (HUVEC) proliferation in vitro, stimulate angiogenesis in vivo, and improve hindlimb ischemia in a mouse model. Our results show that EVs derived from ETV-2 transduced fibroblasts may be a promising product for ischemia treatment. Moreover, in vivo transfection of ETV-2 into fibroblasts may represent a promising strategy to produce EVs and to stimulate neo-angiogenesis.
Acknowledgements This research was funded by the Vietnam National Foundation for Science and Technology Development (NAFOSTED) under Grant Number 106-YS.06-2013.37.

Funding Vietnam National Foundation for Science and Technology Development (NAFOSTED) under Grant Number 106-YS.06-2013.37.

Authors' contributions PVP was responsible for suggesting the idea for this study, creating the experiment design, vector preparation, data analysis, writing the Discussion, preparing the figures, and revising the manuscript. VBN, TTTD, HTNL, LTP were responsible for performing murine model of hindlimb ischemia, evaluation of recovery of damaged limbs after EVs injection. OTH and MTHT were responsible for performing the essays of fibroblast culture, RT-PCR analysis, flow cytometry analysis, and writing the Methods. OTKN and NKP were were responsible for EVs isolation, characterization; performing the HUVEC cultures, Matrigel assays, and writing the Introduction. All authors read and approved the manuscript.

\section{Compliance with ethical standards}

Conflict of interests The authors declare they have no competing interests.

\section{References}

Amann B, Ludemann C, Ruckert R, Lawall H, Liesenfeld B, Schneider M, Schmidt-Lucke J (2008) Design and rationale of a randomized, double-blind, placebo-controlled 
phase III study for autologous bone marrow cell transplantation in critical limb ischemia: the BONe Marrow Outcomes Trial in Critical Limb Ischemia (BONMOTCLI). Vasa 37:319-325

Amann B, Luedemann C, Ratei R, Schmidt-Lucke JA (2009) Autologous bone marrow cell transplantation increases leg perfusion and reduces amputations in patients with advanced critical limb ischemia due to peripheral artery disease. Cell Transplant 18:371-380

Ammar HI, Sequiera GL, Nashed MB, Ammar RI, Gabr HM, Elsayed HE, Sareen N, Rub EA, Zickri MB, Dhingra S (2015) Comparison of adipose tissue- and bone marrowderived mesenchymal stem cells for alleviating doxorubicin-induced cardiac dysfunction in diabetic rats. Stem Cell Res Ther 6:148

Besse B, Charrier M, Lapierre V, Dansin E, Lantz O, Planchard D, Le Chevalier T, Livartoski A, Barlesi F, Laplanche A et al (2016) Dendritic cell-derived exosomes as maintenance immunotherapy after first line chemotherapy in NSCLC. Oncoimmunology 5:e1071008

Booth AM, Fang Y, Fallon JK, Yang JM, Hildreth JE, Gould SJ (2006) Exosomes and HIV Gag bud from endosome-like domains of the $\mathrm{T}$ cell plasma membrane. J Cell Biol 172:923-935

Burger D, Vinas JL, Akbari S, Dehak H, Knoll W, Gutsol A, Carter A, Touyz RM, Allan DS, Burns KD (2015) Human endothelial colony-forming cells protect against acute kidney injury: role of exosomes. Am J Pathol 185:2309-2323

Dai S, Wei D, Wu Z, Zhou X, Wei X, Huang H, Li G (2008) Phase I clinical trial of autologous ascites-derived exosomes combined with GM-CSF for colorectal cancer. Mol Ther 16:782-790

Fan W, Tian XD, Huang E, Zhang JJ (2013) Exosomes from CIITA-transfected CT26 cells enhance anti- tumor effects. Asian Pac J Cancer Prev 14:987-991

Fang S, Xu C, Zhang Y, Xue C, Yang C, Bi H, Qian X, Wu M, Ji $\mathrm{K}$, Zhao $\mathrm{Y}$ et al (2016) Umbilical cord-derived mesenchymal stem cell-derived exosomal micrornas suppress myofibroblast differentiation by inhibiting the transforming growth factor-beta/smad2 pathway during wound healing. Stem Cells Transl Med 5:1425-1439

Fu Y, Guan J, Guo S, Guo F, Niu X, Liu Q, Zhang C, Nie H, Wang Y (2014) Human urine-derived stem cells in combination with polycaprolactone/gelatin nanofibrous membranes enhance wound healing by promoting angiogenesis. J Transl Med 12:274

Furuta T, Miyaki S, Ishitobi H, Ogura T, Kato Y, Kamei N, Miyado K, Higashi Y, Ochi M (2016) Mesenchymal stem cell-derived exosomes promote fracture healing in a mouse model. Stem Cells Transl Med 5:1620-1630

Geiger A, Walker A, Nissen E (2015) Human fibrocyte-derived exosomes accelerate wound healing in genetically diabetic mice. Biochem Biophys Res Commun 467:303-309

Ginsberg M, James D, Ding BS, Nolan D, Geng F, Butler JM, Schachterle W, Pulijaal VR, Mathew S, Chasen ST et al (2012) Efficient direct reprogramming of mature amniotic cells into endothelial cells by ETS factors and TGFbeta suppression. Cell 151:559-575

Ginsberg M, Schachterle W, Shido K, Rafii S (2015) Direct conversion of human amniotic cells into endothelial cells without transitioning through a pluripotent state. Nat Protoc 10:1975-1985

Goto T, Fukuyama N, Aki A, Kanabuchi K, Kimura K, Taira H, Tanaka E, Wakana N, Mori H, Inoue H (2006) Search for appropriate experimental methods to create stable hindlimb ischemia in mouse. Tokai J Exp Clin Med 31:128-132

Gremmels H, Teraa M, Quax PH, den Ouden K, Fledderus JO, Verhaar MC (2014) Neovascularization capacity of mesenchymal stromal cells from critical limb ischemia patients is equivalent to healthy controls. Mol Ther 22:1960-1970

Gupta PK, Chullikana A, Parakh R, Desai S, Das A, Gottipamula S, Krishnamurthy S, Anthony N, Pherwani A, Majumdar AS (2013) A double blind randomized placebo controlled phase I/II study assessing the safety and efficacy of allogeneic bone marrow derived mesenchymal stem cell in critical limb ischemia. J Transl Med 11:143

Han C, Sun X, Liu L, Jiang H, Shen Y, Xu X, Li J, Zhang G, Huang J, Lin Z et al (2016) Exosomes and their therapeutic potentials of stem cells. Stem Cells Int 2016:7653489

Hao C, Shintani S, Shimizu Y, Kondo K, Ishii M, Wu H, Murohara T (2014) Therapeutic angiogenesis by autologous adipose-derived regenerative cells: comparison with bone marrow mononuclear cells. Am J Physiol Heart Circ Physiol 307:H869-H879

He M, Qin H, Poon TC, Sze SC, Ding X, Co NN, Ngai SM, Chan TF, Wong N (2015) Hepatocellular carcinoma-derived exosomes promote motility of immortalized hepatocyte through transfer of oncogenic proteins and RNAs. Carcinogenesis 36:1008-1018

Hu GW, Li Q, Niu X, Hu B, Liu J, Zhou SM, Guo SC, Lang HL, Zhang CQ, Wang Y et al (2015) Exosomes secreted by human-induced pluripotent stem cell-derived mesenchymal stem cells attenuate limb ischemia by promoting angiogenesis in mice. Stem Cell Res Ther 6:10

Iafrati MD, Hallett JW, Geils G, Pearl G, Lumsden A, Peden E, Bandyk D, Vijayaraghava KS, Radhakrishnan R, Ascher E et al (2011) Early results and lessons learned from a multicenter, randomized, double-blind trial of bone marrow aspirate concentrate in critical limb ischemia. J Vasc Surg 54:1650-1658

Jiang ZZ, Liu YM, Niu X, Yin JY, Hu B, Guo SC, Fan Y, Wang Y, Wang NS (2016) Exosomes secreted by human urinederived stem cells could prevent kidney complications from type I diabetes in rats. Stem Cell Res Ther 7:24

Johnson P, Beswick EJ, Chao C, Powell DW, Hellmich MR, Pinchuk IV (2016) Isolation of CD 90 + Fibroblast/Myofibroblasts from human frozen gastrointestinal specimens. J Vis Exp 107:e53691

Katakowski M, Buller B, Zheng X, Lu Y, Rogers T, Osobamiro O, Shu W, Jiang F, Chopp M (2013) Exosomes from marrow stromal cells expressing miR-146b inhibit glioma growth. Cancer Lett 335:201-204

Kawai T, Katagiri W, Osugi M, Sugimura Y, Hibi H, Ueda M (2015) Secretomes from bone marrow-derived mesenchymal stromal cells enhance periodontal tissue regeneration. Cytotherapy 17:369-381

Keller S, Sanderson MP, Stoeck A, Altevogt P (2006) Exosomes: from biogenesis and secretion to biological function. Immunol Lett 107:102-108

Khan M, Nickoloff E, Abramova T, Johnson J, Verma SK, Krishnamurthy P, Mackie AR, Vaughan E, Garikipati VN, 
Benedict C et al (2015) Embryonic stem cell-derived exosomes promote endogenous repair mechanisms and enhance cardiac function following myocardial infarction. Circ Res 117:52-64

Kisselbach L, Merges M, Bossie A, Boyd A (2009) CD90 Expression on human primary cells and elimination of contaminating fibroblasts from cell cultures. Cytotechnology 59:31-44

Lee JK, Park SR, Jung BK, Jeon YK, Lee YS, Kim MK, Kim YG, Jang JY, Kim CW (2013) Exosomes derived from mesenchymal stem cells suppress angiogenesis by downregulating VEGF expression in breast cancer cells. PLoS ONE 8:e84256

Li X, Chen C, Wei L, Li Q, Niu X, Xu Y, Wang Y, Zhao J (2016a) Exosomes derived from endothelial progenitor cells attenuate vascular repair and accelerate reendothelialization by enhancing endothelial function. Cytotherapy 18:253-262

Li X, Jiang C, Zhao J (2016b) Human endothelial progenitor cells-derived exosomes accelerate cutaneous wound healing in diabetic rats by promoting endothelial function. J Diabetes Complications 30:986-992

Liang X, Zhang L, Wang S, Han Q, Zhao RC (2016) Exosomes secreted by mesenchymal stem cells promote endothelial cell angiogenesis by transferring miR-125a. J Cell Sci 129:2182-2189

Liu J, Hao H, Xia L, Ti D, Huang H, Dong L, Tong C, Hou Q, Zhao Y, Liu H et al (2015) Hypoxia pretreatment of bone marrow mesenchymal stem cells facilitates angiogenesis by improving the function of endothelial cells in diabetic rats with lower ischemia. PLoS ONE 10:e0126715

Morita R, Suzuki M, Kasahara H, Shimizu N, Shichita T, Sekiya T, Kimura A, Sasaki K, Yasukawa H, Yoshimura A (2015) ETS transcription factor ETV2 directly converts human fibroblasts into functional endothelial cells. Proc Natl Acad Sci USA 112:160-165

Nahm WK, Zhou L, Falanga V (2002) Sustained ability for fibroblast outgrowth from stored neonatal foreskin: a model for studying mechanisms of fibroblast outgrowth. J Dermatol Sci 28:152-158

Nakamura Y, Miyaki S, Ishitobi H, Matsuyama S, Nakasa T, Kamei N, Akimoto T, Higashi Y, Ochi M (2015) Mesenchymal-stem-cell-derived exosomes accelerate skeletal muscle regeneration. FEBS Lett 589:1257-1265

Park IS, Chung PS, Ahn JC (2014) Enhanced angiogenic effect of adipose-derived stromal cell spheroid with low-level light therapy in hind limb ischemia mice. Biomaterials 35:9280-9289

Park C, Lee TJ, Bhang SH, Liu F, Nakamura R, Oladipupo SS, Pitha-Rowe I, Capoccia B, Choi HS, Kim TM et al (2016) Injury-mediated vascular regeneration requires endothelial ER71/ETV2. Arterioscler Thromb Vasc Biol 36:86-96

Peeters Weem SM, Teraa M, den Ruijter HM, de Borst GJ, Verhaar MC, Moll FL (2016) Quality of life after treatment with autologous bone marrow derived cells in no option severe limb ischemia. Eur J Vasc Endovasc Surg 51:83-89

Pitt JM, Andre F, Amigorena S, Soria JC, Eggermont A, Kroemer G, Zitvogel L (2016) Dendritic cell-derived exosomes for cancer therapy. J Clin Invest 126:1224-1232

Qi X, Zhang J, Yuan H, Xu Z, Li Q, Niu X, Hu B, Wang Y, Li X (2016) Exosomes secreted by human-induced pluripotent stem cell-derived mesenchymal stem cells repair criticalsized bone defects through enhanced angiogenesis and osteogenesis in osteoporotic rats. Int J Biol Sci 12:836-849

Qin Y, Zhou P, Zhou C, Li J, Gao WQ (2014) The adiposederived lineage-negative cells are enriched mesenchymal stem cells and promote limb ischemia recovery in mice. Stem Cells Dev 23:363-371

Saliutin RV, Palianytsia SS, Sirman VM, Panchenko LA, Komarova LS (2014) Transplantation of adipose tissue multipotent stromal cells in the treatment of chronic ischemia of the lower extremities. Klin Khir 7:42-44

Schupp MO, Waas M, Chun CZ, Ramchandran R (2014) Transcriptional inhibition of etv2 expression is essential for embryonic cardiac development. Dev Biol 393:71-83

Shabbir A, Cox A, Rodriguez-Menocal L, Salgado M, Van Badiavas E (2015) Mesenchymal stem cell exosomes induce proliferation and migration of normal and chronic wound fibroblasts, and enhance angiogenesis in vitro. Stem Cells Dev 24:1635-1647

Shen WC, Liang CJ, Wu VC, Wang SH, Young GH, Lai IR, Chien CL, Wang SM, Wu KD, Chen YL (2013) Endothelial progenitor cells derived from Wharton's jelly of the umbilical cord reduces ischemia-induced hind limb injury in diabetic mice by inducing HIF-1alpha/IL-8 expression. Stem Cells Dev 22:1408-1418

Shi X, Richard J, Zirbes KM, Gong W, Lin G, Kyba M, Thomson JA, Koyano-Nakagawa N, Garry DJ (2014) Cooperative interaction of Etv2 and Gata2 regulates the development of endothelial and hematopoietic lineages. Dev Biol 389:208-218

Sun L, Xu R, Sun X, Duan Y, Han Y, Zhao Y, Qian H, Zhu W, $\mathrm{Xu}$ W (2016) Safety evaluation of exosomes derived from human umbilical cord mesenchymal stromal cell. Cytotherapy 18:413-422

Teraa M, Sprengers RW, Schutgens RE, Slaper-Cortenbach IC, van der Graaf Y, Algra A, van der Tweel I, Doevendans PA, Mali WP, Moll FL et al (2015) Effect of repetitive intra-arterial infusion of bone marrow mononuclear cells in patients with no-option limb ischemia: the randomized, double-blind, placebo-controlled Rejuvenating Endothelial Progenitor Cells via Transcutaneous Intra-arterial Supplementation (JUVENTAS) trial. Circulation 131:851-860

van Balkom BW, de Jong OG, Smits M, Brummelman J, den Ouden K, de Bree PM, van Eijndhoven MA, Pegtel DM, Stoorvogel W, Wurdinger T et al (2013) Endothelial cells require miR-214 to secrete exosomes that suppress senescence and induce angiogenesis in human and mouse endothelial cells. Blood 121:3997-4006

van der Pol E, Boing AN, Harrison P, Sturk A, Nieuwland R (2012) Classification, functions, and clinical relevance of extracellular vesicles. Pharmacol Rev 64:676-705

Van Pham P, Bui N-TA, Trinh N-L, Phi TL, Phan KN, Vu BN (2014) A comparison of umbilical cord blood-derived endothelial progenitor and mononuclear cell transplantation for the treatment of acute hindlimb ischemia. Biomed Res and Ther 1:1-12

Van Pham P, Vu NB, Nguyen HT, Huynh OT, Truong MT (2016) Significant improvement of direct reprogramming efficacy of fibroblasts into progenitor endothelial cells by ETV2 and hypoxia. Stem Cell Res Ther 7:104 
Vu NB, Bui AN-T, Ngoc-Le Trinh V, Phi LT, Phan NK, Van Pham P (2014) A comparison of umbilical cord bloodderived endothelial progeni-tor and mononuclear cell transplantation for the treatment of acute hindlimb ischemia. Biomed Res Ther 1:1-12

Vu NB, Ngoc-Le Trinh V, Phi LT, Phan NK, Van Pham P (2015) Human menstrual blood-derived stem cell transplantation for acute hind limb ischemia treatment in mouse models. In: Regenerative medicine (Springer), pp 205-215

Vu NB, Phi LT, Dao TT-T, Le HT-N, Van Pham P (2016) Adipose derived stem cell transplantation is better than bone marrow mesenchymal stem cell transplantation in treating hindlimb ischemia in mice. Biomed Res Ther 3:46

Wang X, Huang W, Liu G, Cai W, Millard RW, Wang Y, Chang J, Peng T, Fan GC (2014) Cardiomyocytes mediate antiangiogenesis in type 2 diabetic rats through the exosomal transfer of miR-320 into endothelial cells. J Mol Cell Cardiol 74:139-150

Wen D, Peng Y, Liu D, Weizmann Y, Mahato RI (2016) Mesenchymal stem cell and derived exosome as small RNA carrier and immunomodulator to improve islet transplantation. J Control Release 238:166-175

Wu Z, Zeng Q, Cao K, Sun Y (2016) Exosomes: small vesicles with big roles in hepatocellular carcinoma. Oncotarget 7:60687-60697

Xie N, Li Z, Adesanya TM, Guo W, Liu Y, Fu M, Kilic A, Tan T, Zhu H, Xie X (2016) Transplantation of placenta- derived mesenchymal stem cells enhances angiogenesis after ischemic limb injury in mice. J Cell Mol Med 20:29-37

Yoshida S, Yoshimoto H, Hirano A, Akita S (2016) Wound healing and angiogenesis through combined use of a vascularized tissue flap and adipose-derived stem cells in a rat hindlimb irradiated ischemia model. Plast Reconstr Surg 137:1486-1497

Yuan H, Guan J, Zhang J, Zhang R, Li M (2016) Exosomes secreted by human urine-derived stem cells accelerate skin wound healing by promoting angiogenesis in rat. Cell Biol Int. doi:10.1002/cbin.10615

Zhang B, Adesanya TM, Zhang L, Xie N, Chen Z, Fu M, Zhang J, Zhang J, Tan T, Kilic A et al (2014) Delivery of placentaderived mesenchymal stem cells ameliorates ischemia induced limb injury by immunomodulation. Cell Physiol Biochem 34:1998-2006

Zhang J, Guan J, Niu X, Hu G, Guo S, Li Q, Xie Z, Zhang C, Wang Y (2015) Exosomes released from human induced pluripotent stem cells-derived MSCs facilitate cutaneous wound healing by promoting collagen synthesis and angiogenesis. J Trans1 Med 13:49

Zhao Y, Sun X, Cao W, Ma J, Sun L, Qian H, Zhu W, Xu W (2015) Exosomes derived from human umbilical cord mesenchymal stem cells relieve acute myocardial ischemic injury. Stem Cells Int 2015:761643 